\title{
Identification and characterization of a hemagglutinin gene from Prevotella intermedia
}

\author{
Seok-Woo Lee ${ }^{1 *}$, Masaaki Okamoto² ${ }^{2}$ and Kai P. Leung ${ }^{3}$ \\ ${ }^{1}$ Professor, Department of Periodontology and Dental Education, School of Dentistry, Chonnam National University, Gwangju, Republic of Korea \\ ${ }^{2}$ Professor, Department of Oral Bacteriology, Tsurumi University School of Dental Medicine, Yokohama, Japan \\ ${ }^{3}$ Director, Dental and Craniofacial Trauma Research and Tissue Regeneration Directorate, U.S. Army Institute of Surgical Research, JBSA Fort Sam, Houston, \\ TX, USA
}

In this study, we describe the cloning of a gene encoding hemagglutinin from Prevotella intermedia to characterize hemagglutinin function and elucidate its possible role in the infectious process mediated by the organism. We screened genomic libraries created in Escherichia coli JM109, using antibodies against $P$. intermedia, and the positive clones were subsequently tested for their hemagglutinating activity, using rabbit red blood cells. We isolated a clone of strain 0543 in which, a 3.6-kb P. intermedia chromosomal DNA fragment was inserted into the pUC18 plasmid. Our deletion analysis-based subcloning procedures identified a hemagglutinin gene-designated phg. The open-reading frame of phg encoded a $35-\mathrm{kDa}$ protein, and the expression of a recombinant protein of the predicted size was observed in a fusion protein expression system. While the DNA analysis of phg revealed no homology to known DNA sequences, the putative promoter, ribosome binding, and transcriptional termination sequence were found in the flanking DNA regions. In the N-terminus of the deduced amino acid sequence, we found a consensus leader peptide sequence for secretory proteins. These findings indicate that hemagglutinin might be expressed on the surface of $P$. intermedia to mediate its function.

Key Words: Hemagglutination; Periodontitis; Prevotella; Virulence

(c) This is an open-access article distributed under the terms of the Creative Commons Attribution Non-Commercial License (http://creativecommons.org/licenses/by-nc/4.0) which permits unrestricted noncommercial use, distribution, and reproduction in any medium, provided the original work is properly cited.

\section{Introduction}

Prevotella intermedia is a gram-negative black-pigmented anaerobe, which has been implicated in many types of human periodontal diseases, due in part to its frequent recovery from lesions [1-4] and possession of putative virulence factors [5]. Many virulence factors associated with the pathogenic characteristics of $P$. intermedia have been identified, some of which may be involved in bacterial coaggre- gation [4,6-8], the stimulation of host immune T-cells [9], or damage to host tissues [10-12]. Among these virulence factors, hemagglutinin has been suggested as a possible adhesin, mediating the attachment of oral microorganisms to host tissues in the oral cavity [13-15]. Previous results in our laboratory showed that $P$. intermedia mediated hemagglutination and that this activity may be associated with fimbriae $[16,17]$.

However, the exact mechanism of how $P$. intermedia

Received March 5, 2021; Revised April 7, 2021; Accepted April 24, 2021

*Corresponding author: Seok-Woo Lee, Department of Periodontology and Dental Education, School of Dentistry, Chonnam National University, 33, Yongbong-ro, Buk-gu, Gwangju 61186, Republic of Korea.

Tel: +82-62-530-5820, Fax: +82-62-530-5810, E-mail: swlee@chonnam.ac.kr 
mediates hemagglutination has not been determined since the bacterial components responsible for hemagglutinating activity have not yet been isolated and characterized. In the present study, the molecular cloning of a hemagglutinin gene of $P$. intermedia was pursued to elucidate the role of hemagglutinin in the infectious process, which may lead to a better understanding of the pathogenesis of periodontal disease mediated by $P$. intermedia.

\section{Materials and Methods}

\section{Bacterial strains and growth conditions}

P. intermedia was maintained on blood agar plates consisting of 3\% Trypticase soy broth (Becton Dickinson Microbiology Systems, Cockeysville, MD, USA), 0.5\% yeast extract (Difco Laboratories, Detroit, MI, USA), 5\% sheep blood, $5 \mu \mathrm{g} / \mathrm{mL}$ hemin, and $1 \mu \mathrm{g} / \mathrm{mL}$ menadione. For growth in liquid media, $P$. intermedia was cultured in Todd-Hewitt broth (Becton Dickinson) supplemented with $5 \mu \mathrm{g} / \mathrm{mL}$ hemin and $1 \mu \mathrm{g} / \mathrm{mL}$ menadione. The cells were grown and maintained at $37^{\circ} \mathrm{C}$ in an anaerobic chamber containing an atmosphere of $85 \% \mathrm{~N}_{2}, 10 \% \mathrm{H}_{2}$, and $5 \% \mathrm{CO}_{2}$. E. coli strains were grown aerobically at $37^{\circ} \mathrm{C}$ on Luria-Bertani (LB) medium consisting of $1 \%$ Bacto-tryptone (Difco), $1 \% \mathrm{NaCl}$, and $0.5 \%$ yeast extract. For solid medium, $1.5 \%$ agar was added to LB broth. When indicated, $50 \mu \mathrm{g} / \mathrm{mL}$ ampicillin was added to the media to select recombinant clones of the $E$. coli strains. The bacterial strains used in the present study are shown in Table 1.

\section{Plasmids and recombinant DNA techniques}

The plasmid vectors used in the present study are shown in Table 1. All of the restriction enzymes and modifying enzymes used in this study were purchased from Promega Corporation (Madison, WI, USA) unless otherwise indicated, and used according to the manufacturer's directions. Ligations were performed at $16^{\circ} \mathrm{C}$ using T4 DNA ligase. Ligation mixtures were used to transform E. coli JM109 to acquire ampicillin resistance. After overnight incubation, the selected clones were screened by crack preparations, and clones showing plasmids of the appropriate size were further analyzed by restriction mapping of the plasmid DNA isolated using the Wizard Miniprep (Promega) Kit. Chromosomal DNA was isolated using the Wizard Genomic DNA Purification Kit (Promega). Chromosomal and plasmid DNA were separated on $0.8 \%$ agarose gels by electrophoresis according to standard procedures. DNA fragments were recovered from agarose gels using the Wizard DNA Clean-up System (Promega) according to the manufacturer's directions.

Table 1. Bacterial strains and plasmids

\begin{tabular}{|c|c|c|}
\hline Strains/Plasmid & Characteristics & Reference \\
\hline \multicolumn{3}{|l|}{ Strains } \\
\hline 17 & Clinical isolate of $P$. intermedia & 6,7 \\
\hline JM109 & $\begin{array}{l}\left.\text { [F'traD36 proAB lacI }{ }^{9} \mathrm{Z} \Delta \mathrm{M} 15\right] \mathrm{D}(\mathrm{lac}-\text { pro } \mathrm{AB}) \text { e14-(mcrA) endA1 recA1 gyrA96 thi-1 hsdRI7 } \\
\left(\mathrm{rk}^{-} \mathrm{mk}^{+}\right) \text {supE44 relA1 }\end{array}$ & Promega \\
\hline 0543 & $\begin{array}{l}\text { Recombinant clone containing the } 3.6-\mathrm{kb} \\
\text { BamHI DNA insert in pUC18 }\end{array}$ & This study \\
\hline 0543-1 & Recombinant clone containing the $1.1-\mathrm{kb} B a m H I-B g I I$ DNA fragment in pUC18 & This study \\
\hline 0543-2 & Recombinant clone containing the $2.5-\mathrm{kb}$ BamHI-BglI DNA fragment in pUC18 & This study \\
\hline 0543-3 & $\begin{array}{l}\text { Recombinant clone containing the } 1.2-\mathrm{kb} \\
\text { SspI DNA fragment in pUC18 }\end{array}$ & This study \\
\hline 0543-4 & $\begin{array}{l}\text { Recombinant clone containing the } 2.0-\mathrm{kb} \\
\text { EcoRV-BamHI and } 0.2-\mathrm{kb} \text { EcoRV-BamHI fragment in pUC18 }\end{array}$ & This study \\
\hline PH001 & Recombinant clone containing the 930-bp ORF of phg in pMAL-c2 & This study \\
\hline \multicolumn{3}{|c|}{ 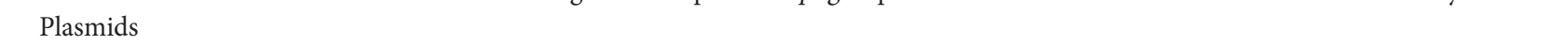 } \\
\hline pUC18 & lacIq, lacZa, Amp ${ }^{\mathrm{r}}, 2.7 \mathrm{~kb}$ & Pharmacia \\
\hline pPI0543 & The 3.6-kb P. intermedia DNA insert, Amp $\mathrm{r}^{\mathrm{r}}, 6.3 \mathrm{~kb}$ & This study \\
\hline pMAL-c2 & $\mathrm{malE}, l a c I^{\mathrm{q}}, \mathrm{Amp}^{\mathrm{r}}, 6.4 \mathrm{~kb}$ & New England Biolab \\
\hline
\end{tabular}




\section{Construction of genomic library, subcloning, and sequencing}

The genomic library of $P$. intermedia 17 was constructed as follows. The 1-5 kb chromosomal DNA fragments partially digested with Sau3AI or HindIII were ligated into pUC18, and the resultant recombinant plasmids were transformed into JM109. About 3,500 recombinant clones were screened with the antibody produced against whole $P$. intermedia 17 cells. Some of the positive clones were subsequently screened with the antibody produced against $P$. intermedia fimbriae [16]. The resulting positive clones were tested for hemagglutinating activity. The hemagglutinating clones were selected and subcloning procedures were performed by deletion analysis.

Sequencing was performed for both DNA strands at the University of Florida DNA Sequence Core facility using Taq Dye Primer and Taq Dye Terminator cycle sequencing protocols with fluorescent primers and dideoxynucleotides, respectively.

\section{Polymerase chain reaction}

The 930-bp open reading frame (ORF) of the hemagglutinin gene was amplified using polymerase chain reaction (PCR). Primers 5'-GGGGAAGCTTTTATGGCAATACTACTACTCT (KAL 33), and 5'-AAGCGGTACATACTCATTATA (KAL 34) were used as the reverse and forward primers, respectively. The DNA template used for PCR was recombinant plasmid pPI0543 containing the whole $3.6 \mathrm{~kb}$ insert in pUC18. A HindIII restriction site (underlined above) was engineered into the primer KAL 33 to facilitate the insertion of the PCR product into the HindIII cloning site of the expression vector pMAL-c2. Terminal GGGG bases were added to the primer KAL33 to promote cleavage at the HindIII restriction sites. Inverse PCR procedures was performed as described previously to amplify the flanking regions to obtain the entire genetic sequence [18].

\section{Hemagglutination assay}

The hemagglutination assay was performed using procedures described previously [16]. Briefly, rabbit red blood cells were washed with phosphate-buffered saline (PBS, pH 7.2) and resuspended in the same buffer to make a $2 \%(\mathrm{v} / \mathrm{v})$ suspension. The bacterial suspensions were washed three times in PBS and adjusted to an $\mathrm{OD}_{550}$ of 2.0. Two-fold serial dilutions of the bacterial suspensions $(50 \mu \mathrm{L})$ were made in PBS, and $50 \mu \mathrm{L}$ of the washed erythrocyte suspension was added to microtiter plate wells. The mixture was shaken for 30 minutes on a vibrator and stored overnight at $4^{\circ} \mathrm{C}$ before visual inspection.

\section{Expression of the recombinant protein}

To study the expression of the recombinant protein and further purify a recombinant hemagglutinin, a Protein Fusion \& Purification System (New England Biolab, Beverly, MA, USA) was used. The 930-bp ORF of the hemagglutinin gene was amplified by PCR as described above. The amplified product was treated with Klenow enzyme for bluntending and then digested with HindIII. This DNA fragment was then inserted into the pMAL-c2 vector, which was cut with XmnI and HindIII. The resultant recombinant plasmid was transformed into competent JM109 cells, and the recombinant clone was selected by restriction mapping. One of these clones, which contained the correct recombinant plasmid size, was identified, designated as PH001, and used for further studies. Strain PH001 was grown in LB broth containing ampicillin $(100 \mu \mathrm{g} / \mathrm{mL})$ to an $\mathrm{OD}_{600}$ of 0.3 , and Isopropyl $\beta$-d-1-thiogalactopyranoside (IPTG) was then added to the culture to a final concentration of $0.3 \mathrm{mM}$. The culture was allowed to grow for another two to three hours. For further isolation of the fusion protein, PH001 cells were harvested and centrifuged. The pellets were resuspended in column buffer (20 mM Tris- $\mathrm{HCl}, 200 \mathrm{mM}$ $\mathrm{NaCl}$, and $1 \mathrm{mM} \mathrm{EDTA}$, and kept at $-20^{\circ} \mathrm{C}$ overnight. The pellets were then thawed and subjected to sonication for preparation of the lysate. The lysate was further processed by centrifugation to obtain crude cell extract for isolation of the fusion protein. The remaining pellet was resuspended in column buffer for analysis by gel electrophoresis. To isolate the fusion protein, the crude extract was mixed with amylose resin and incubated for 15 minutes on ice. After the mixture supernatant was removed by centrifugation, the remaining resin was washed in column buffer and 
resuspended in sodium dodecyl sulfate-polyacrylamide gel electrophoresis (SDS-PAGE) sample buffer for analysis. The proteins were separated on $12 \%$ separating gel and visualized by staining with Coomassie blue. This sample represented the fusion protein bound to amylose.

\section{Gene accession number}

The gene sequence reported in this study was submitted to GenBank with an accession number AF017417.

\section{Results}

\section{Restriction mapping and analysis of subclones}

Recombinant clones positively reacting to the anti-P. intermedia whole-cell antibody were subsequently screened with an antibody prepared against the partially-purified fimbrial preparation of $P$. intermedia. The resultant positive clones were tested for hemagglutination, of which six clones were found to exhibit hemagglutinating actvity. The restriction mapping data suggested that these clones contained 0.8-3.7 kb chromosomal DNA inserts in pUC18 (data not shown). One clone, designated 0543 , which contained

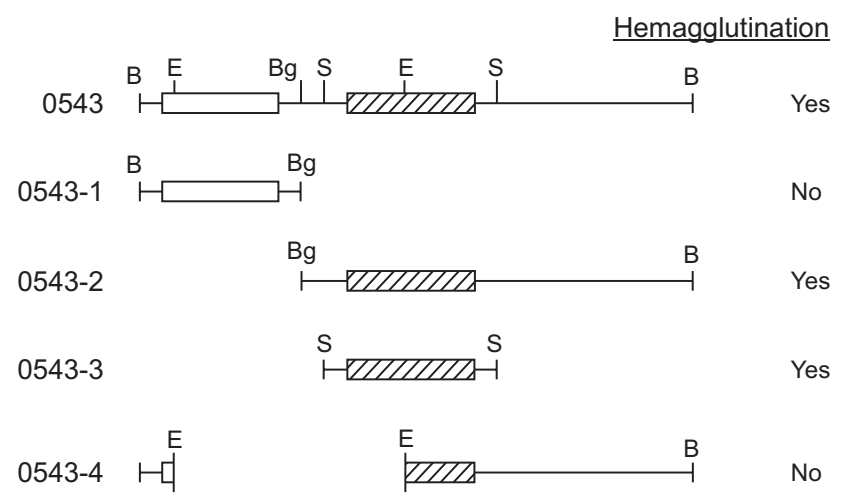

Fig. 1. Subcloning of the 3.6-kb insert of strain 0543 and the hemagglutinating activity of the subclones. Strain 0543 contains the whole 3.6-kb BamHI insert, 0543-1 contains the 1.1-kb BamHI-BglI DNA fragment, 0543-2 contains the 2.5-kb BamHI-BglI DNA fragment, 0543-3 contains the 1.2-kb SspI DNA fragment, and 0543-4 contains the 2.0-kb EcoRV-BamHI and the 0.2-kb EcoRV-BamHI fragment in pUC18. The enzyme restriction sites are shown: B, BamHI; E, EcoRV; Bg, BglI; and S, SspI. The 930-bp open reading frame of the phg gene, ORF1, is shown as ZIIIIII. The open reading frame homologous to the hbp gene, ORF2, is shown as a 3.6-kb DNA fragment, was selected for further study. To verify the origin of the DNA insert, Southern blot analysis was performed using a digoxigenin-labeled 3.6-kb DNA fragment as a probe. The results confirmed that the $3.6-\mathrm{kb}$ insert originated from the $P$. intermedia chromosome (data not shown). The 3.6-kb DNA insert was found to possess two distinct ORFs. Subcloning procedures using deletion analysis identified a 930-bp ORF, which conferred hemagglutinating activity to the E. coli strain, as shown in Fig. 1. The hemagglutinating activity of the recombinant clones compared with those of P. intermedia and the control E. coli strain is shown in Fig. 2. Subclone 0543-1 containing a 1.1-kb BamHI-BglI DNA fragment of the 942-bp ORF was unable to agglutinate rabbit red blood cells. However, subclones 0543-2 and 0543-3, both of which contained a 930bp ORF, possessed hemagglutinating activity. In contrast, subclone 0543-4, which had an incomplete 930-bp ORF, did not possess hemagglutinating activity.

\section{Sequence analysis of phg}

The nucleotide sequence analysis of the cloned hemagglutinin gene did not reveal any significant homology to

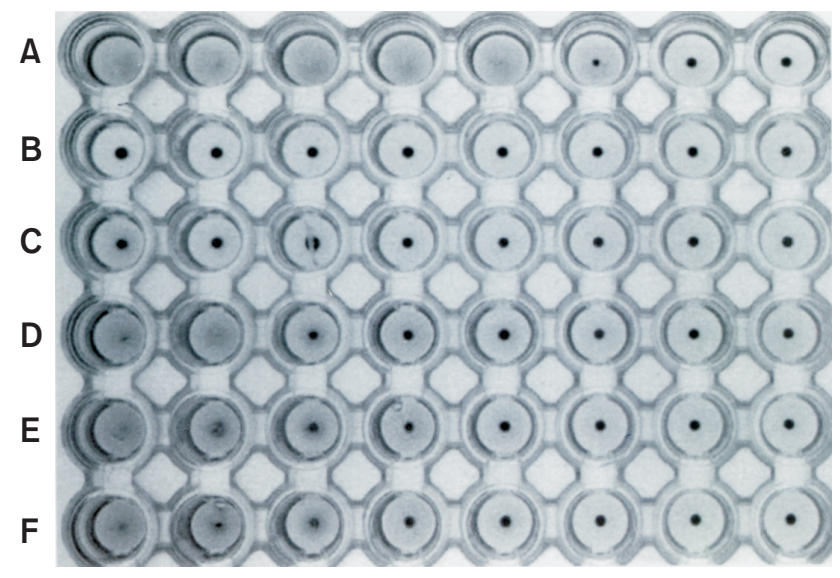

Fig. 2. Hemagglutination by the recombinant clones and $P$. intermedia. (A) P. intermedia 17, (B) JM109 containing pUC18, (C) Strain 0543-4, (D) Strain 0543, (E) Strain 0543-2, and (F) Strain 0543-3. All bacterial suspensions were washed three times in phosphate-buffered saline and adjusted to an $\mathrm{OD}_{550}$ of 2.0. The bacterial suspensions were two-fold serially diluted to test hemagglutinating activity with rabbit red blood cells. Strong agglutinations appeared as clumps of erythrocytes distributed in the wells. When not agglutinated, the erythrocytes settled to the bottom of the wells and formed solid buttons. 
known gene sequences. The mol\% GC content of the entire 3.6-kb insert was $44.9 \%$. The \%GC of phg was $45.6 \%$, which was consistent with the known $P$. intermedia chromosomal mol\% GC content. Along with the ORF, a putative Pribnow Box (-10 TATA), a ribosomal binding site, and a potential stem-loop structure downstream of the stop codon were found. The consensus signal sequence (KRYILIIIVALASIGSAIAG) is also identified in the aminoterminal region of the deduced amino acid sequence (Fig. 3). The phg sequences, with around $97 \%$ homology, are consistently found in other clinical isolates of $P$. intermedia, including strains 17-2, KCOM 1944, KCOM 1933, KCOM 2836, KCOM 2734, KCOM 2837, OMA14, and 25611, as determined by the BLAST program (https://blast.ncbi.nlm. nih.gov/Blast.cgi). The derived amino acid sequence was 310 residues in length with a size of 35,740 daltons. The

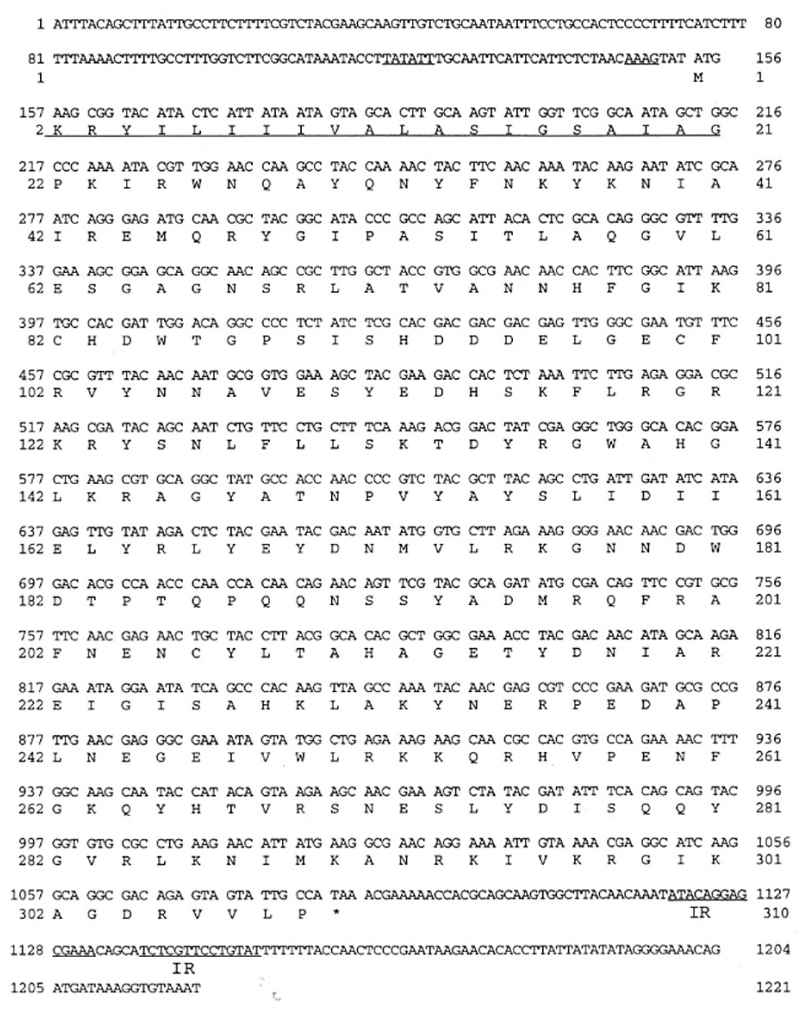

Fig. 3. Nucleotide sequence of phg and the flanking regions and a deduced amino acid sequence of phg. The putative promoter site, -10 region (TATATT) and a potential ribosome binding site (AAAG) are underlined. A potential stem-loop structure found downstream of the stop codon is marked as IR. The consensus signal sequence (KRYILIIIVALASIGSAIAG) is underlined in the amino-terminal region of the deduced amino acid sequence. protein was found to be basic and hydrophilic with an estimated isoelectric point of 9.5. A consensus signal peptide for secretory protein was found in the amino-terminal region, and the estimated cleavage site was ideally consistent with the rules of von Heijine ( -3 and -1$)$ for gram-negative bacteria [19].

\section{Expression of recombinant hemagglutinin}

To study the expression of the recombinant protein, a Protein Fusion \& Purification System (New England Biolab, Beverly, MA, USA) was used. The recombinant hemagglutinin was expressed and detected by the fusion protein expression system. The ORF of phg was placed under the control of the tac promoter and translational signal from the vector $\mathrm{pMAL}-\mathrm{c} 2$ to produce a fusion protein consisting of maltose-binding protein and recombinant hemagglutinin. The recombinant $E$. coli clone expressing the fusion protein, PH001, was selected and grown as described in the Materials and Methods section. As shown in Fig. 4, the recombinant hemagglutinin was produced as a fusion protein with a maltose-binding protein, resulting in a ca. $77-\mathrm{kD}$

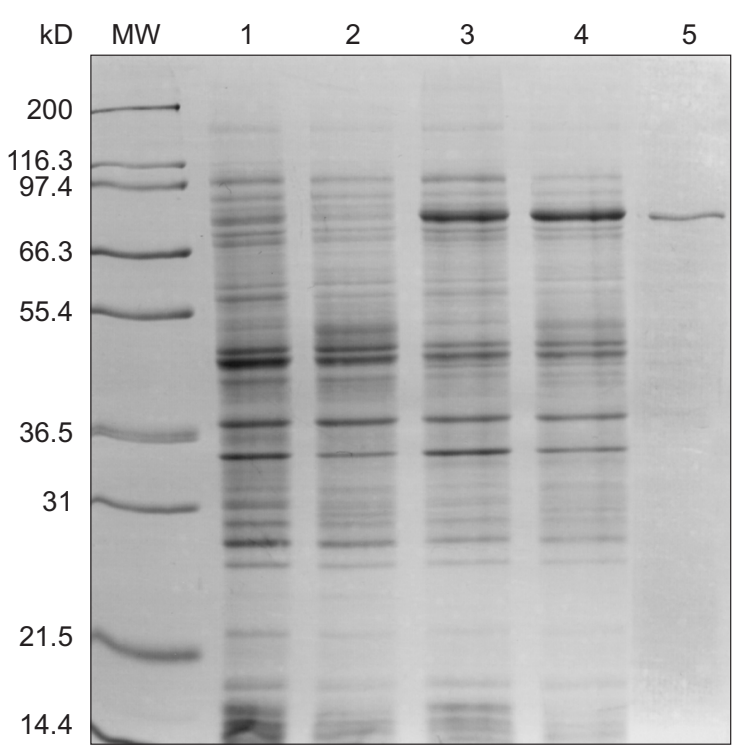

Fig. 4. Sodium dodecyl sulfate-polyacrylamide gel electrophoresis of the lysates of strain PH001. The protein profiles of lysates obtained under different induced conditions are shown: Lane I, uninduced; Lane 2, 1-h IPTG induction; Lane 3, 2-h IPTG induction; Lane 4, the soluble fraction (supernatant) of the IPTG-induced cell lysate; Lane 5, purified fusion protein. For details, refer to the main text. 
protein. The expression was significantly increased when it was induced with IPTG (lanes 2 and 3), compared to that of uninduced growth (lane 1). The $77-\mathrm{kD}$ fusion protein was shown as a single band in lane 6 , which was isolated by binding to the amylose-bound resin. The fusion protein was highly expressed in the soluble crude extract samples and the insoluble matter of the lysate (lanes 4 and 5).

\section{Discussion}

In the present study, a hemagglutinin gene, designated phg, of P. intermedia was cloned and expressed in E. coli to determine the putative roles of hemagglutinin as a virulence factor. Among the recombinant clones selected based upon their reactivity with polyclonal anti-P. intermedia whole-cell and fimbrial antibodies, strain 0543 consistently exhibited the strongest activity. The DNA sequence analysis of this clone revealed the presence of ORFs in the 3.6-kb insert. One ORF with a size of $930 \mathrm{bp}$, ORF1, was identified as the phg ORF.

Further, the other ORF, ORF2, with a size of 940 bp was found to be homologous to the heme-binding protein gene (hbp) of Bacteroides fragilis, a closely related black-pigmented bacterium [20]. To gain more information regarding ORF2, inverse PCR procedures were performed to amplify the flanking regions to obtain the entire genetic sequence of ORF2. It was found that the 1.7-kb putative hbp gene of $P$. intermedia was highly homologous ( $75 \%$ similarity) to $h b p$ of $B$. fragilis and that this gene was ubiquitous in other oral black-pigmented bacteria. The two phg and hbp genes were located in tandem within a 548-bp interval. The possible existence of gene clusters of hemagglutinin and heme-binding protein is very interesting since it is known that bacterial genes with related functions are frequently located very close to each other [21,22]. Even though the exact roles of hemagglutinin and the heme-binding protein of $P$. intermedia are not known, it can be postulated that hemagglutinin may be involved in promoting the attachment of the bacteria to red cells and that the heme-binding protein could help the bacteria utilize heme present in red cells to survive and proliferate inside the host. In contrast, sequence analysis of the putative hemagglutinin gene showed no significant homology to the known DNA con- tained in databases. Nucleotide and amino acid sequence analysis did not reveal the presence of any other potential hemagglutinin genes in the genomes of several clinical isolates of $P$. intermedia as determined by BLAST search (https://blast.ncbi.nlm.nih.gov/Blast.cgi).

However, phg contained the consensus signal sequence characteristic of secretory proteins, suggesting that this gene may encode a protein that is transported and expressed on the surface of the bacterial cell [23,24]. To mediate hemagglutination, it may be essential for the bacteria to express hemagglutinin on its surface. In the deduced amino acid sequence of the phg gene, a region of short basic amino acids followed by long hydrophobic amino acids and short polar amino acids were found in the aminoterminal portion (Fig. 3). Alanines were found at -3 and -1 positions from the putative cleavage site. These are consistent with the consensus signal sequences for secretory proteins of gram-negative bacteria $[25,26]$. The recombinant hemagglutinin was expressed using a fusion protein system. A single $77-\mathrm{kD}$ band was detected, as a result of the fusion between the $42-\mathrm{kD}$ maltose-binding protein and the 35$\mathrm{kD}$ hemagglutinin. This result suggests that the phg gene was successfully expressed in its correct size in E. coli.

A separate study found that the hemagglutinating activity of the clinical isolates of $P$. intermedia was closely associated with the presence of the hemagglutinin gene (phg) [7] among the strains. This result also supports the hypothesis that phg may play a crucial role in the hemagglutinating activity of $P$. intermedia.

Recent biochemical data from our laboratory indicated that a putative hemagglutinin of $P$. intermedia isolated from the fimbriae was a $3.8-\mathrm{kD}$ protein [17]. The present study, however, found that the putative hemagglutinin was a 35-kD protein. This suggests that two different hemagglutinins may function in P. intermedia. The presence of multiple hemagglutinins has been shown in P. gingivalis $[13,14,27,28]$. Even though the exact functions of the multiple hemagglutinins have not yet been adequately elucidated, it appears that multiple hemagglutinins could be involved in a variety of functions including the adherence to other host tissues as well as to red cells. It would be interesting to determine whether multiple hemagglutinin genes are also present in P. intermedia. While the $3.8-\mathrm{kD}$ 
hemagglutinin was isolated from the fimbriae, the origin of the $35-\mathrm{kD}$ hemagglutinin is not known. Immunological studies using antibodies prepared against the purified recombinant hemagglutinin could elucidate the origin of the 35-kD hemagglutinin.

While this study is one of the first reports of gene cloning of the putative virulence factors from $P$. intermedia, there remain technical difficulties for further studies of $P$. intermedia virulence since no gene transfer system is currently available for $P$. intermedia. To ultimately prove that $p h g$ is a hemagglutination gene, phg isogenic mutants deficient in hemagglutinating activity should be constructed. We anticipate that the information on the hemagglutinin gene of $P$. intermedia may lead to further genetic developments for studying $P$. intermedia pathogenicity and a better understanding of the pathogenesis of periodontal disease.

\section{Acknowledgements}

This investigation was supported in part by a Public Health Service grant DE 05429 from the National Institute of Dental Research, a Research Development Award from the University of Florida, a Grant-in-Aid for Scientific Research (C) No. 14571756 from the Ministry of Education, Science, and Culture of Japan, and Chonnam National University, Korea.

\section{Conflicts of Interest}

The authors declare that they have no competing interests.

\section{ORCID}

\author{
Seok-Woo Lee \\ https://orcid.org/0000-0002-7589-282X \\ Masaaki Okamoto \\ https://orcid.org/0000-0001-7448-7016 \\ Kai P. Leung \\ https://orcid.org/0000-0003-0156-8151
}

\section{References}

1. Socransky SS, Haffajee AD, Cugini MA, Smith C, Kent RL
Jr. Microbial complexes in subgingival plaque. J Clin Periodontol 1998;25:134-144. doi: 10.1111/j.1600-051x.1998. tb02419.x.

2. Gharbia SE, Haapasalo M, Shah HN, Kotiranta A, Lounatmaa K, Pearce MA, Devine DA. Characterization of Prevotella intermedia and Prevotella nigrescens isolates from periodontic and endodontic infections. J Periodontol 1994;65:56-61. doi: 10.1902/jop.1994.65.1.56.

3. Maeda N, Okamoto M, Kondo K, Ishikawa H, Osada R, Tsurumoto A, Fujita H. Incidence of Prevotella intermedia and Prevotella nigrescens in periodontal health and disease. Microbiol Immunol 1998;42:583-589. doi: 10.1111/ j.1348-0421.1998.tb02328.x.

4. Kamaguch A, Nakayama K, Ohyama T, Watanabe T, Okamoto M, Baba H. Coaggregation of Porphyromonas gingivalis and Prevotella intermedia. Microbiol Immunol 2001;45:649-656. doi: 10.1111/j.1348-0421.2001. tb01298.x.

5. Dahlén GG. Black-pigmented gram-negative anaerobes in periodontitis. FEMS Immunol Med Microbiol 1993;6:181192. doi: 10.1111/j.1574-695X.1993.tb00323.X.

6. Nesbitt WE, Fukushima H, Leung KP, Clark WB. Coaggregation of Prevotella intermedia with oral Actinomyces species. Infect Immun 1993;61:2011-2014. doi: 10.1128/ IAI.61.5.2011-2014.1993.

7. Okamoto M, Maeda N, Kondo K, Leung KP. Hemolytic and hemagglutinating activities of Prevotella intermedia and Prevotella nigrescens. FEMS Microbiol Lett 1999;178:299304. doi: 10.1111/j.1574-6968.1999.tb08691.x.

8. Hamada S, Amano A, Kimura S, Nakagawa I, Kawabata S, Morisaki I. The importance of fimbriae in the virulence and ecology of some oral bacteria. Oral Microbiol Immunol 1998;13:129-138. doi: 10.1111/j.1399-302x.1998. tb00724.x.

9. Leung KP, Torres BA. Prevotella intermedia stimulates expansion of Vbeta-specific CD4(+) T cells. Infect Immun 2000;68:5420-5424. doi: 10.1128/iai.68.9.54205424.2000 .

10. Beem JE, Nesbitt WE, Leung KP. Identification of hemolytic activity in Prevotella intermedia. Oral Microbiol Immunol 1998;13:97-105. doi: 10.1111/j.1399-302x.1998.tb00719. $\mathrm{x}$.

11. Dorn BR, Leung KL, Progulske-Fox A. Invasion of human oral epithelial cells by Prevotella intermedia. Infect Immun 1998;66:6054-6057. doi: 10.1128/IAI.66.12.60546057.1998.

12. Silva TA, Rodrigues PH, Ribeiro RN, Noronha FS, Farias Lde M, Carvalho MA. Hemolytic activity of Prevotella intermedia and Prevotella nigrescens strains: influence of abiotic factors in solid and liquid assays. Res Microbiol 2003;154:29-35. doi: 10.1016/s0923-2508(02)00003-7.

13. Progulske-Fox A, Rao V, Han N, Lepine G, Witlock J, Lantz M. Molecular characterization of hemagglutinin genes of 
periodontopathic bacteria. J Periodontal Res 1993;28(6 Pt 2):473-474. doi: 10.1111/j.1600-0765.1993.tb02106.x.

14. Lee SW, Hillman JD, Progulske-Fox A. The hemagglutinin genes hagB and hagC of Porphyromonas gingivalis are transcribed in vivo as shown by use of a new expression vector. Infect Immun 1996;64:4802-4810. doi: 10.1128/ IAI.64.11.4802-4810.1996.

15. Murakami Y, Higuchi N, Nakamura H, Yoshimura F, Oppenheim FG. Bacteroides forsythus hemagglutinin is inhibited by N-acetylneuraminyllactose. Oral Microbiol Immunol 2002;17:125-128. doi: 10.1046/j.09020055.2001.00093.x.

16. Leung KP, Fukushima H, Nesbitt WE, Clark WB. Prevotella intermedia fimbriae mediate hemagglutination. Oral Microbiol Immunol 1996;11:42-50. doi: 10.1111/j.1399302x.1996.tb00335.x.

17. Leung K, Nesbitt WE, Okamoto M, Fukushima H. Identification of a fimbriae-associated haemagglutinin from Prevotella intermedia. Microb Pathog 1999;26:139-148. doi: 10.1006/mpat.1998.0258.

18. Green MR, Sambrook J. Inverse Polymerase Chain Reaction (PCR). Cold Spring Harb Protoc 2019;2019(2). https://doi. org/10.1101/pdb.prot095166.

19. von Heijne G. Membrane protein assembly: rules of the game. Bioessays 1995;17:25-30. doi: 10.1002/bies. 950170107.

20. Otto BR, Kusters JG, Luirink J, de Graaf FK, Oudega B. Molecular characterization of a heme-binding protein of Bacteroides fragilis BE1. Infect Immun 1996;64:4345-4350. doi: 10.1128/IAI.64.10.4345-4350.1996.

21. Tamames J, Casari G, Ouzounis C, Valencia A. Conserved clusters of functionally related genes in two bacterial genomes. J Mol Evol 1997;44:66-73. doi: 10.1007/ p100006122.

22. Willems RJ, Geuijen C, van der Heide HG, Renauld G,
Bertin P, van den Akker WM, Locht C, Mooi FR. Mutational analysis of the Bordetella pertussis fim/fha gene cluster: identification of a gene with sequence similarities to haemolysin accessory genes involved in export of FHA. Mol Microbiol 1994;11:337-347. doi: 10.1111/j.1365-2958. 1994.tb00314.x.

23. Alam M, Miyoshi SI, Tomochika KI, Shinoda S. Purification and characterization of novel hemagglutinins from Vibrio mimicus: a 39-kilodalton major outer membrane protein and lipopolysaccharide. Infect Immun 1996;64:4035-4041. doi: 10.1128/IAI.64.10.4035-4041.1996.

24. Menozzi FD, Boucher PE, Riveau G, Gantiez C, Locht C. Surface-associated filamentous hemagglutinin induces autoagglutination of Bordetella pertussis. Infect Immun 1994;62:4261-4269. doi: 10.1128/IAI.62.10.42614269.1994.

25. Nielsen H, Engelbrecht J, Brunak S, von Heijne G. Identification of prokaryotic and eukaryotic signal peptides and prediction of their cleavage sites. Protein Eng 1997;10:1-6. doi: 10.1093/protein/10.1.1.

26. Jackson CA, Hoffmann B, Slakeski N, Cleal S, Hendtlass AJ, Reynolds EC. A consensus Porphyromonas gingivalis promoter sequence. FEMS Microbiol Lett 2000;186:133-138. doi: 10.1111/j.1574-6968.2000.tb09094.x.

27. Han N, Lepine G, Whitlock J, Wojciechowski L, ProgulskeFox A. The porphyromonas gingivalis prtP/kgp homologue exists as two open reading frames in strain 381. Oral Dis 1998;4:170-179. doi: 10.1111/j.1601-0825.1998.tb00275. $\mathrm{x}$.

28. Nakayama K, Ratnayake DB, Tsukuba T, Kadowaki T, Yamamoto K, Fujimura S. Haemoglobin receptor protein is intragenically encoded by the cysteine proteinaseencoding genes and the haemagglutinin-encoding gene of Porphyromonas gingivalis. Mol Microbiol 1998;27:51-61. doi: 10.1046/j.1365-2958.1998.00656.x. 